\title{
SPECTROPHOTO-ELECTRICAL SENSITIVITY OF BOURNONITE AND PYRARGYRITE.
}

\author{
By W. W. Coblentz and J. F. Eckford.
}

\section{ABSTRACT.}

The present paper, considered in connection with previously published data on proustite, represents a study of the effect of chemical constitution upon spectrophotoelectrical sensitivity. Experimental data are given on the effect of temperature and of the intensity of the radiation stimulus upon the spectrophoto-electrical sensitivity of bournonite, ${ }_{3}\left(\mathrm{Cu}_{2}, \mathrm{~Pb}\right) \mathrm{S} \mathrm{Sb}_{2} \mathrm{~S}_{3}$, and of pyrargyrite, $\mathrm{Ag}_{3} \mathrm{SbS}_{3}$. The observations on the latter are compared with similar data previously published on proustite, $\mathrm{Ag}_{3}$ $\mathrm{AsS}_{3}$. The results obtained are in agreement with the previously formulated (B. S. Sci. Papers, No. 398$)$ general characteristics of spectrophoto-electrical conduction in solids.

\section{CONTENTS.}

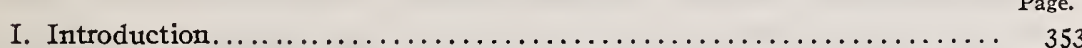

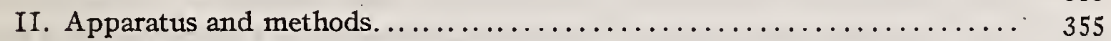

III. Spectrophoto-electrical data on bournonite $\ldots \ldots \ldots \ldots \ldots \ldots \ldots \ldots \ldots \ldots . \quad 357$

I. Description of the material examined ............... 357

2. Reaction-Time................................ 357

3. Spectrophoto-electrical sensitivity of different crystals....... 357

4. Effect of intensity of the radiation stimulus.............. 36 I

5. Effect of temperature............................. $36 \mathrm{r}$

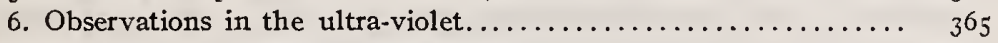

IV. Spectrophoto-electrical data on pyrargyrite.................... 366

I. Description of the material examined ................ ${ }_{3}^{6} 7$

2. Reaction-Time.................................... 367

3. Effect of intensity of the radiation stimulus............. 368

V. Summary

\section{INTRODUCTION.}

The present paper gives the results of a continuation of previous work on the spectrophoto-electrical properties of various substances, ${ }^{1}$ the chief point of interest being the effect of chemical composition upon photosensitivity. In this connection it will be of interest to point out certain similarities between the photoelectrical reaction spectra of chemically related substances, which

1 General Survey (Bismuthinite), B. S. Sci. Papers, No. 322; Molybdenite, B. S. Sci. Papers, No. 338. Silver Sulphide, B. S. Sci. Papers, No. 344; Thalofide, B. S. Sci. Papers, No. 380 ; Positive and Negative Conductivity Phenomena, B. S. Sci. Papers, No. 398; Proustite, B. S. Sci. Papers, No. 4I2; and Argentite (in press). 
remind one of the similarities found in the transmission spectra of the great groups of chemically related compounds. For example, it will be shown in the discussion of the data on pyrargyrite that, as previously observed in absorption spectra of various substances, the spectrophoto-electrical reaction spectrum of the double sulphide of silver and of antimony (pyrargyrite $\mathrm{Ag}_{3} \mathrm{SbS}_{3}$ ) is not the composite of the spectrophoto-electrical reactions of the constituent sulphides of these two metals. On the other hand, as observed in absorption spectra, there is a similarity in the spectrophoto-electrical reaction spectra of pyrargyrite and proustite $\left(\mathrm{Ag}_{3} \mathrm{AsS}_{3}\right)$ which are similar in chemical structure. $^{2}$

In passing it is relevant to record that the intrinsic photoelectrical sensitivity of bournonite and pyrargyrite is low in comparison with selenium, which makes spectral investigations difficult. Another point of interest worth noting is that in many of these photosensitive substances the reaction is confined to two often sharply defined spectral regions.

Furthermore, even in the most sharply defined bands of selective spectrophoto-electrical sensitivity-for example, $\mathrm{TICl}, \mathrm{PbI}_{2}$, etc.-a common characteristic is an abnormally high reaction on the short wave length side of the maximum and an abnormally low reaction on the long wave length side of the maximum. In this respect the general trend of the spectrophoto-electrical reaction curves are just the reverse of the curves of selective (metallic) reflection and anomalous dispersion, which are abnormally low on the short wave length side and abnormally high on the long wave length side of the absorption band.

In the search for an explanation of photosensitivity it was pointed out in a previous paper ${ }^{3}$ that the one property which is common to all these photo-electrically active substances is an abnormally high absorption (and a possible anomalous dispersion) in the short wave lengths extending from the ultra-violet into the visible spectrum. While no systematic search as yet appears to have been made for anomalous dispersion, ${ }^{4}$ it is not unreasonable

\footnotetext{
2 From unpublished data on the chloride, bromide, and iodide of thallium (some samples of which were kindly supplied by the Case Research Laboratory) it appears that the position of the maximum ( $\mathrm{TICl}$ at $0.37 \mu$, TlBrat $0.4 \mathrm{I} \mu$, TII at $0.46 \mu$, and $\mathrm{PbI}_{2}$ at $0.52 \mu$ ) of photo-electrical sensitivity, which is a sharp narrow line, shifts to the longer wave lengths with increase in atomic weight. This shift of the maximum is similar to the photo-electrical reactions in gas-ionic photo-electric cells of the alkali metals and to the infra-red selective reflection spectra of sulphates, carbonates, etc.

${ }^{3}$ B. S. Sci. Papers, 17, p. 180; 1921 .

- Excepting a recent note on Selenium, by Weld, Phys. Rev. (2) 19, p. $4 \mathrm{r}_{4}, 1922$, in which he states that there is strong indication of anomalous dispersion, suggesting an absorption band, in the vicinity of wave length $0.6 \mu$.
} 
to suppose that such a condition exists, especially when the evidence (selective reflection and absorption) is so strong in molybdenite, proustite, etc.

Selective reflection and absorption, and anomalous dispersion are cited merely to emphasize that this spectral region, on the basis of the electromagnetic theory of light, is one of optical instability; and it is not unreasonable to suppose that in at least some substances exhibiting abnormal absorption and anomalous dispersion some frequencies of the exciting radiation can effect electrical conduction. In this connection it is well to remember, however, that while the optical resonance theory is very enticing the question arises why the photo-electrical sensitivity is so commonly found localized in spots. Evidently the whole subject needs further investigation. From (unpublished) photo-electrical data on $\mathrm{PbI}_{2}, \mathrm{TlCl}$, etc., it appears that it will be profitable to examine the reflection, transmission, and refraction in the spectral region in which these substances react photo-electrically.

In, the present paper it will be shown that in bournonite, as previously observed in stibnite and molybdenite, with decrease in temperature the photo-electrical reaction grows more rapidly in intensity in the short wave lengths than in the long wave lengths. On the other hand, in pyrargyrite, as previously observed in proustite and cuprous oxide, with decrease in temperature the photo-electrical reaction grows more rapidly in intensity in the long wave lengths than in the short wave lengths.

\section{APPARATUS AND METHODS.}

For determining the photo-electrical sensitivity from $0.44 \mu$ in the visible spectrum to $3 \mu$ in the infra-red the spectroradiometric apparatus consisted of a mirror spectrometer, a quartz prism, and a 500-watt gas-filled tungsten lamp, described in previous papers. ${ }^{5}$ The radiation intensities, $\mathrm{E}=\mathrm{I}, \mathrm{E}=6.4$, etc., were applied in the form of an equal energy spectrum by varying the current through the lamp, as in previous work.

In the visible spectrum the observations were supplemented by measurements with a spectrometer with lenses of $30 \mathrm{~cm}$ focal length and $5 \mathrm{~cm}$ diameter and a light-flint glass prism, giving a large dispersion. The source of light was a 600-watt gas-filled tungsten (spereoptican) lamp, calibrated for equal energy. 
The measurements in the ultra-violet (to $0.25 \mu$ ) were made with a spectropyrheliometer ${ }^{6}$ having lenses and a prism of quartz. The source of radiation was a 60o-watt quartz mercury vapor lamp. Exact measurements were made, using the intense emission lines at $0.305 \mu, 0.313 \mu, 0.334 \mu, 0.365 \mu, 0.405 \mu$, and $0.436 \mu$ reduced to the same radiometric intensity (as that of the $0.334 \mu$ line) by placing suitable diaphragms over the lens used to focus the lamp upon the spectrometer slit.

In these tests the photo-electrically sensitive substance was connected directly in circuit with a d'Arsonval galvanometer, a high resistance, and a suitable potential obtained from "dry batteries." Bournonite has a high specific resistance while pyrargyrite has a low resistance. Hence the usual procedure was to apply sufficient potential to obtain a suitable galvanometer deflection. At room temperature 2.6 to 20 volts sufficed, but at low temperatures the resistance was so high that 50 to 80 volts were required to obtain the desired photo-electric deflections.

By direct experiment it was found that at any given temperature the photo-electrical sensitivity was proportional to the "dark current." Hence the magnitude of the "dark current" may be taken as a measure of the photo-electrical sensitivity. As a general rule, with decrease in temperature the electrical resistance (as well as the intrinsic photo-electrical sensitivity) is greatly increased. In fact, in some of the substances examined the resistance was so high at low temperatures that it would have been impractical to apply sufficient potential in order to obtain the data for dark currents comparable with those at room temperatures. At the present stage of our knowledge of photo-electrical sensitivity (on material so variable in this property for a given temperature) it does not appear of great importance whether the intrinsic photoelectrical sensitivity at, say, $-100^{\circ} \mathrm{C}$. is Io or $\mathrm{I}, 000$ times that at $20^{\circ} \mathrm{C}$.

In general, it was desired to map the relative spectrophotoelectric responses for a given temperature, and hence no attempt was made to reduce the observations to the same intrinsic sensitivity which would have required closely the same "dark current" at all temperatures. However, in studying the effect of intensity of the radiation stimulus upon the spectrophoto-electrical reaction both the temperature and the applied voltage (to give the same dark current) remained constant.

6 B. S. Sci. Papers, 16, p. 233; 1920. 
III. SPECTROPHOTO-ELECTRICAL DATA ON BOURNONITE.

Bournonite is a complex sulphide of copper, lead, and antimony, ${ }_{3}\left(\mathrm{Cu}_{2} \mathrm{~Pb}\right) \mathrm{SSb}_{2} \mathrm{~S}_{3}$, crystallizing in the orthorhombic system. Since the sulphides of copper and of lead are not sensitive photoelectrically, it was of interest to determine the resultant spectrophoto-electrical reaction when combined with the photosensitive antimony sulphide.

\section{DESCRIPTION OF THE MATERIAL EXAMINED.}

The samples of bournonite examined came from ${ }^{7}$ Neudorf, Harz, Germany. The original crystals were of large size-from 4 to $5 \mathrm{~cm}$ in length and 2 to $3 \mathrm{~cm}$ in cross section. They were black in color, the fresh cleavage surfaces having a bright metallic luster. The samples examined were cleavage pieces broken from these large crystals. The fracture being conchoidal, the surfaces were curved and indented unless cut flat with a knife. Five samples were examined. The dimensions were as follows: No. I, 8 by 4 by I mm; No. 2,9 by 3 by I; No. 3,8 by 2 by I. 5 ; No. 4,4 by 2.5 by 2 ; No. 5,6 by 4 by 1 .

For electrodes the ends and a short distance along the sides of all these samples were covered with Wood's alloy in order to obtain symmetrical electrical conduction through the crystal. The (No. 36) copper wire terminals were then soldered to these electrodes. Each sample was then mounted permanently upon a fiber base.

\section{REACTION-TIME.}

The electrical properties of this mineral seemed to differ considerably from that of stibnite. On constant voltage the resistance did not decrease with time and there did not appear to be any difference in the electrical (dark) conductivity or in the photoelectrical sensitivity on reversal of the current through the crystal. The photo-electrical reaction seemed to be practically instantaneous at all temperatures, and the recovery after exposure seemed to be as quick as the response on exposure.

\section{SPECTROPHOTO-ELECTRICAL SENSITIVITY OF DIFFERENT CRYSTALS.}

It was found that the photo-electrical sensitivity in bournonite is localized in spots, as previously observed in molybdenite. Moreover, the general outline of the spectrophoto-electrical reaction curves was found to vary for different crystals, for different samples of the same crystal, and for different parts of the same sample.

'Purchased from Ward's Nat. Sci, Estab., Rochester, N. Y. 
In some cases the photo-electrical sensitivity curves exhibit distinct maxima in the visible spectrum and at $0.95 \mu$ in the infrared, while in other parts of the crystal the infra-red maximum is barely perceptible. This is well illustrated in Figure $\mathrm{x}$, in which curve $B$ represents the data obtained on one side of sample No.

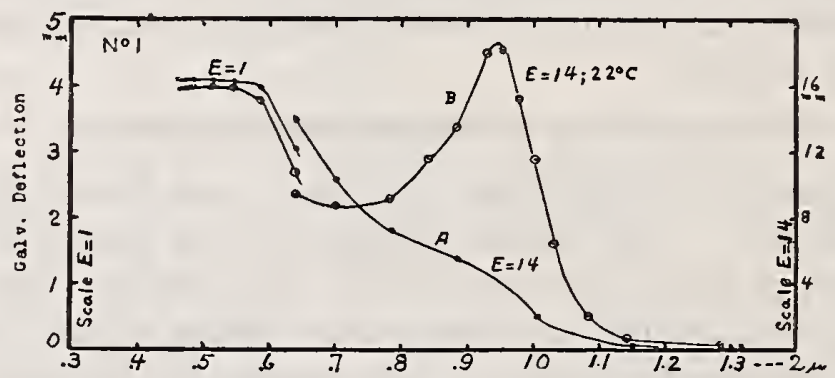

FIG. I.-Photo-electrical sensitivity of different parts of a crystal of bournonite (No. I).

I, while curve $A$ represents the observations made on the opposite side of the crystal section. The pair of curves on the right-hand side of this illustration were obtained on exposure of the crystal to an equal energy spectrum of radiation intensity, $\mathrm{E}=\mathrm{I} 4$, while those in the visible spectrum were obtained with an intensity of $\mathrm{E}=\mathrm{r}$. Because of the low photo-electrical sensitivity in the

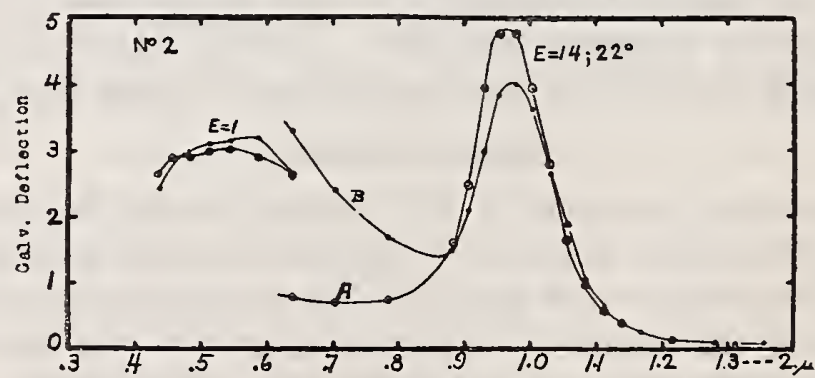

FIG. 2.-Spectrophoto-electrical sensitivity of different parts of a crystal (No. 2) of bournonite.

infra-red it was necessary to use a high intensity. The complete curves for $\mathrm{E}=\mathrm{I}$ are given in Figure 4 .

In Figure 2 the circles $(\odot \odot \odot)$ represent observations on a worked surface (cut flat) of sample No. 2, the scale of deflections for $\mathrm{E}=\mathrm{I}_{4}$ being ten times that of $\mathrm{E}=\mathrm{r}$. The dots (•••) represent the observations on the opposite (unworked cleavage) side of the crystal, the scale of the deflections for $\mathrm{E}=\mathrm{I} 4$ being three and one-half times that of $E=I$. From this it appears that, as previously observed in argentite, superficial working of the mineral 
has no marked effect upon the maximum of spectrophoto-electrical sensitivity. (The difference between the two curves at $0.6 \mu$ to $0.8 \mu$ is no doubt owing to some cause other than mechanical working.)

In Figure 3 the circles represent the observations on one cleavage surface and the dots represent the data obtained on the opposite

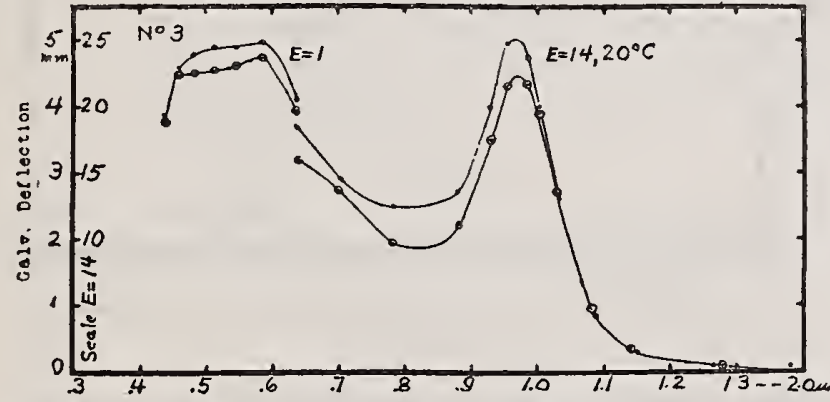

FIG. 3.- Spectrophoto-electrical sensitivity of different parts of a crystal (No.3) of bournonite.

side of sample No. 3. In this sample, as in Figure 2, the maxima at $0.55 \mu$ and $0.97 \mu$ are well defined and there is a close parallelism in the general outline of the sensitivity curves for the two sides of the crystal.

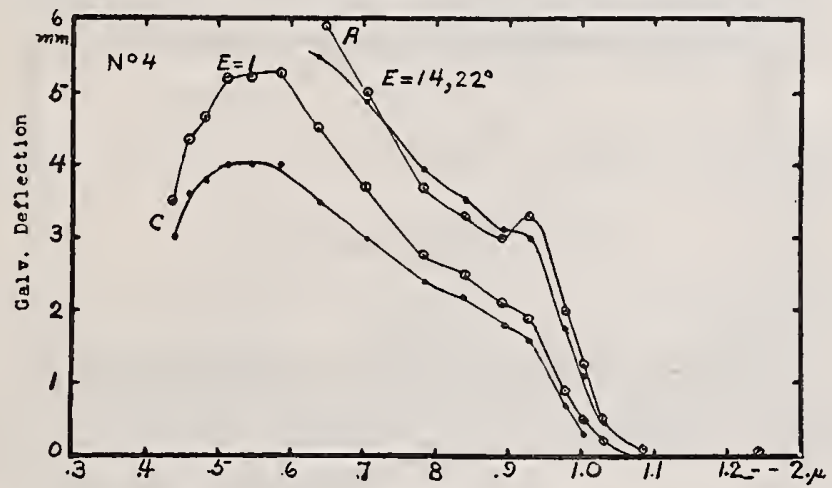

FIG. 4.-Spectrophoto-electrical sensitivity of different parts of a crystal (No. 4) of bournonite.

In Figure 4 the complete spectrophoto-electrical reaction curves of sample No. 4 are given for $\mathrm{E}=\mathrm{I}$ and $\mathrm{E}=\mathrm{I} 4$, the scale of the galvanometer deflections of the latter being four times that of $\mathrm{E}=\mathrm{I}$. In this illustration the circles $(\odot \odot \odot)$ represent the photoelectrical sensitivity along one edge of the crystal while the dots (- -) represent the observations on the same cleavage $721^{\circ}-22-2$ 
surface but along the central axis of the crystal. The spectrophoto-electrical sensitivity seems to be fairly uniform throughout this sample. There is a conspicuous absence of the band at $0.95 \mu$, which was observed also in one part of sample No. I.

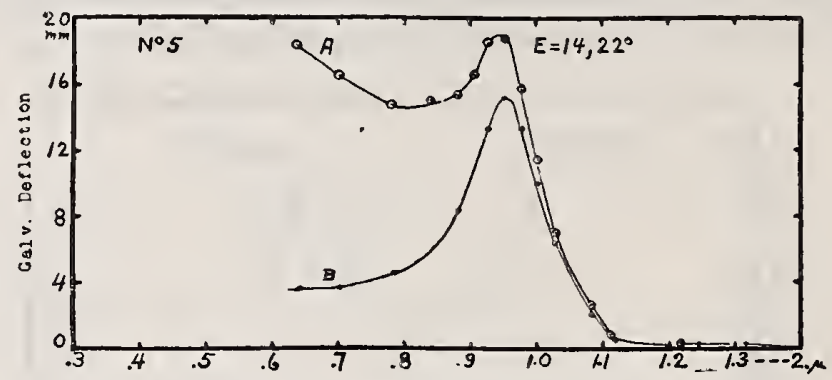

FIG. 5.-Spectrophoto-electrical sensitivity of different parts of a crystal (No.5) of bournonite.

In Figure 5 curves $A$ and $B$ depict the spectrophoto-electrical sensitivity of two opposite sides of bournonite sample No. 5 . They have a conspicuous maximum in common at $0.95 \mu$ but differ greatly in sensitivity in the visible spectrum. Similar curves were observed in Figures 2 and 3.

From the foregoing observations it appears that bournonite has a wide maximum of photo-electrical sensitivity in the violet

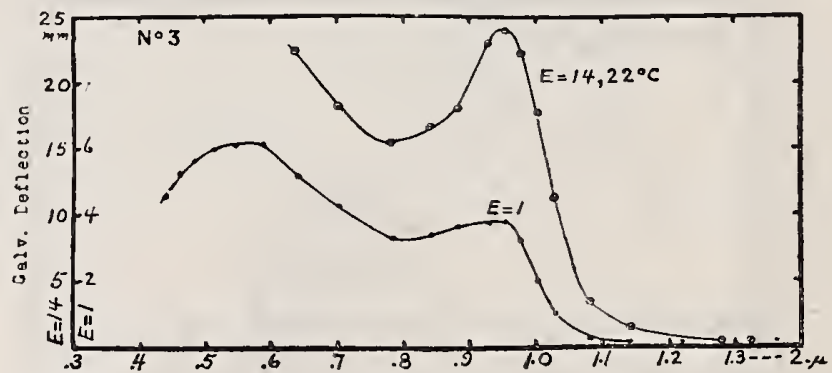

FIG. 6.-Effect of intensity upon the spectrophoto-electrical sensitivity of bournonite (No. 3).

end of the visible spectrum and a second, though not always welldefined, maximum at $0.95 \mu$ in the infra-red. The photo-electrical reaction spectrum of bournonite is entirely different from that of stibnite, $\mathrm{Sb}_{2} \mathrm{~S}_{3}$ (which has its maximum sensitivity at $0.77 \mu$ ), and this reaction spectrum seems to be characteristic of this mineral. 


\section{EFFECT OF INTENSITY OF THE RADIATION STIMULUS.}

The effect of the intensity of the radiation stimulus upon the spectrophoto-electrical reaction of bournonite samples Nos. 3 and 5 is depicted in Figures 6 and 7 , respectively, the applied intensities being $\mathrm{E}=\mathrm{I}$ and $\mathrm{E}=\mathrm{I} 4$.

As found in previous investigations on selenium, molybdenite, argentite, etc., the higher intensity produces the greatest reaction in the infra-red. In the present material the maximum at $0.95 \mu$ emerges very sharply from the rest of the curve under a stimulus of $E=I 4$. At $0.95 \mu$ the ratio of galvanometer deflections for $\mathrm{E}=\mathrm{I} 4: \mathrm{I}$ is 6.3 , while at $0.7 \mu$ it is $4 . \mathrm{I}$.

Further observations on the effect of intensity are illustrated in Figures 9 and ro, the latter being especially noticeable for the

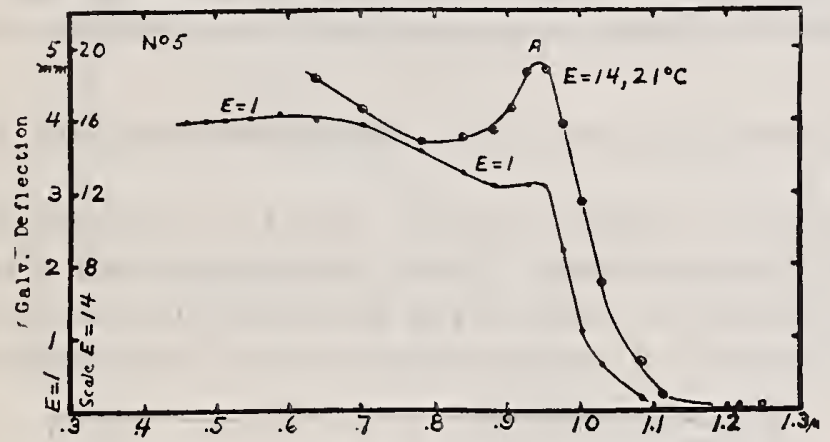

FIG. 7.-Effect of intensity upon the spectrophoto-electrical sensitivity of bournonite (No. 5).

rapid increase in the reaction in the infra-red with increase in intensity.

\section{EFFECT OF TEMPERATURE.}

The effect of lowering the temperature of stibnite, and practically all the photosensitive substances thus far examined, is to confine the photo-electrical reaction to a narrow band in the infra-red, the substance being relatively insensitive to radiation stimuli of other wave lengths.

Bournonite appears to be an exception to this rule. The intrinsic photo-electrical sensitivity is greatly increased at low temperatures as usual. But instead of the infra-red maximum emerging sharply from and greatly exceeding the rest of the spectrophoto-electrical reaction curve (especially the violet end of it) at the lowest temperatures, as observed in pyrargyrite, the maximum reaction in the violet usually continues dominant, even 
at the lowest temperatures. As a consequence, the infra-red maximum merely shifts toward the short wave lengths, as observed in other photo-sensitive substances, but it does not emerge

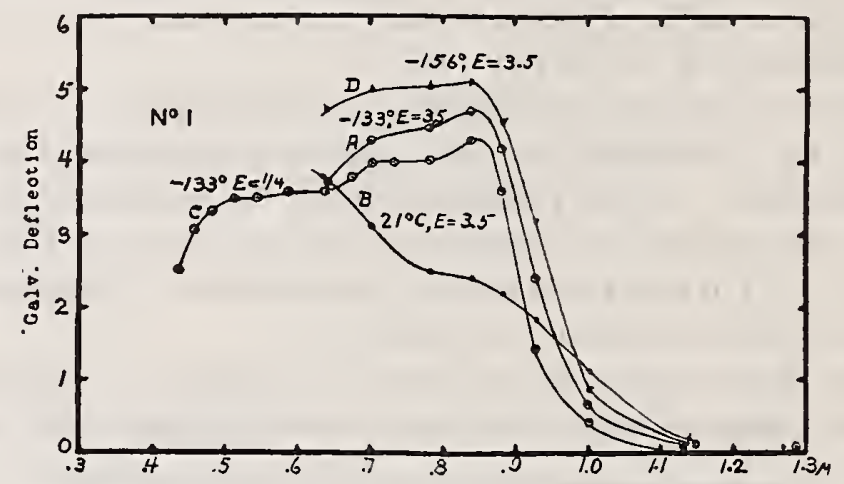

Fig. 8.-Effect of temperature upon the spectrophoto-electrical sensitivity of bournonite (No. I).

distinctly from the rest of the spectrophoto-electrical reaction curve.

Bournonite has a high resistance, and at low temperatures it is practically nonconducting. It was therefore impractical to apply sufficient voltage to maintain the same dark current (at all temperatures) which is a measure of the intrinsic photo-electrical sen-

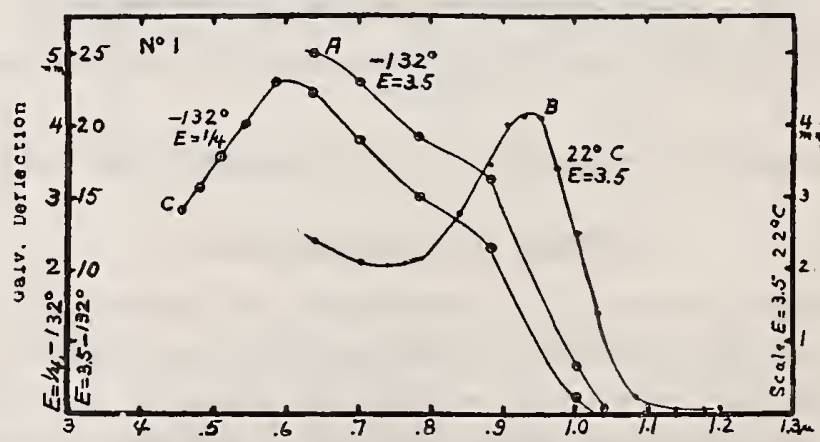

FIG. 9.-Effect of temperature upon the spectrophoto-electrical sensitivity of bournonite (No. $x$ ).

sitivity. However, since we are interested in the relative spectral reactions at any given temperature (the isothermal spectrophotoelectrical reaction curve) and not in the absolute galvanometer deflections at different temperatures, the data given in the following illustrations are not plotted to the same scale. Thus, in Figure 8 , curve $B$, the observed galvanometer deflections at $2 \mathrm{I}^{\circ} \mathrm{C}$. were twice the values indicated by the ordinates (used for curves 
$C$ and $D$ ), in millimeters, while for curve $A$ the observed deflections were in centimeters, and they are one-half the values of the indicated ordinates.

In Figure 8 is illustrated the effect of change in temperature upon the spectrophoto-electrical sensitivity of the bright, fractured side of sample No. I. Additional data for $22^{\circ} \mathrm{C}$. and $\mathrm{E}=\mathrm{I} 4$ are given in curve $A$, Figure I. Similarly, Figure 9, curve $B$, gives data on the spectrophoto-electrical reactions of the opposite side of sample No. I at $22^{\circ} \mathrm{C}$. (see curve $B$, Figure I, for data using $\mathrm{E}=\mathrm{I} 4$ ), while curve $A$ illustrates similar observations at $-132^{\circ} \mathrm{C}$., using $\mathrm{E}=3.5$. Curve $C$ is for a radiation intensity of $\mathrm{E}=0.25$. These two illustrations show an interesting interchange

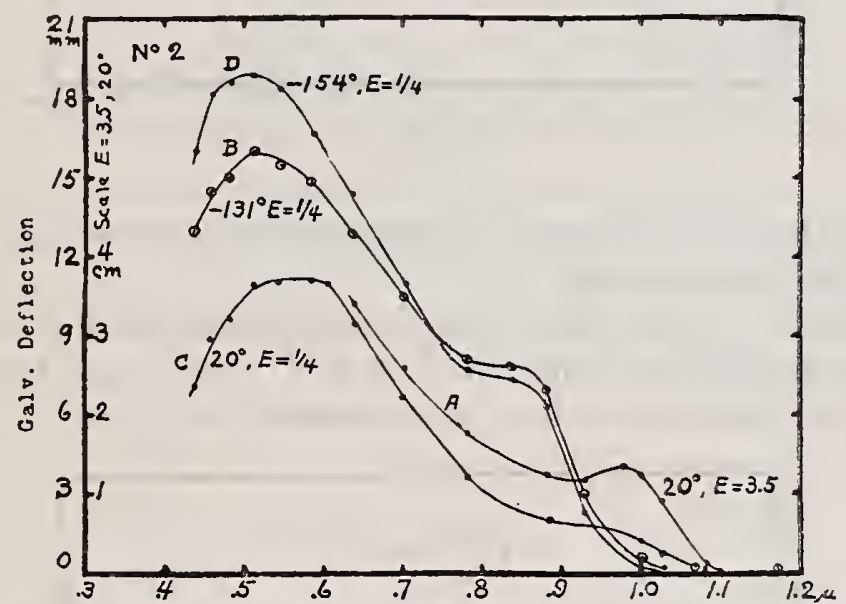

Firg. ro.-Effect of temperature upon the spectrophoto-electrical sensitivity of bournonite (No. 2).

of the relative intensities of the spectral reactions in the vioiet and infra-red maxima, with decrease in temperature.

In Figure ro curves $C$ and $A$ illustrate the spectrophoto-electrical reactions of sample No. 2 at $20^{\circ} \mathrm{C}$. for $\mathrm{E}=0.25$ and $\mathrm{E}=3.5$, respectively, the ordinates being in millimeters for curve $C$ and in centimeters (separate scale) for curve $A$. Curves $B$ and $D$ give similar spectral reactions at $-\mathrm{I}_{3} \mathrm{I}^{\circ}$ and $-\mathrm{I}_{5} 4^{\circ} \mathrm{C}$., respectively, the deflections being in millimeters. But, as already explained, owing to the rapid decrease in the dark conductivity, there is but little increase in the size of the galvanometer deflections at the lowest temperature, in spite of the fact that the intrinsic sensitivity is higher at $-154^{\circ}$ than at $-\mathrm{I}_{3} \mathrm{I}^{\circ}$. The maximum reaction remains in the violet at all temperatures investigated. 
In Figure II are illustrated the spectrophoto-electrical reactions of sample No. 3 at 20 and $-I I 5^{\circ} \mathrm{C}$., respectively. The infra-red maximum at $0.96 \mu$ shifts to $0.85 \mu$ at low temperatures (see curves $C$ and $B$ for $\mathrm{E}=0.25$ ), but it does not become more

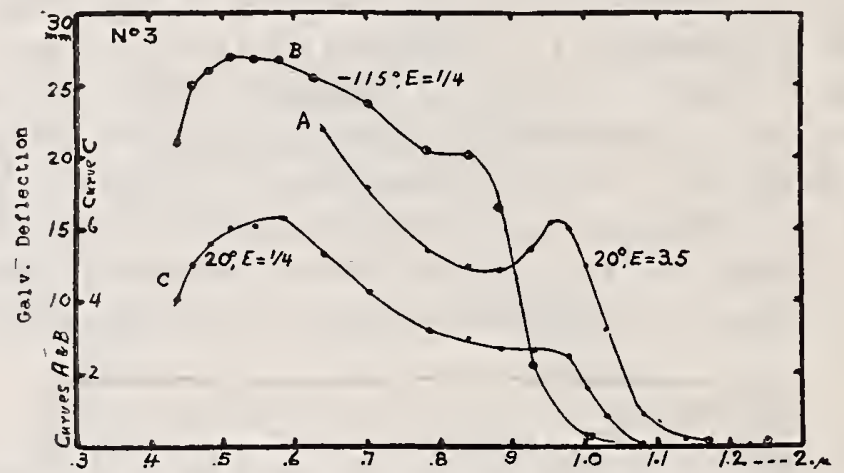

FIG. II.-Effect of temperature upon the spectrophoto-electrical sensitivity of bournonite (No. 3).

sharply defined with decrease in temperature, as observed in some photosensitive substances.

In Figure $\mathrm{I}_{2}$ are given the spectrophoto-electrical reaction curves of bournonite sample No. 4 at $20^{\circ} \mathrm{C}$., and $-153^{\circ} \mathrm{C}$., respectively, the deflections being in millimeters for curve $A$ and in

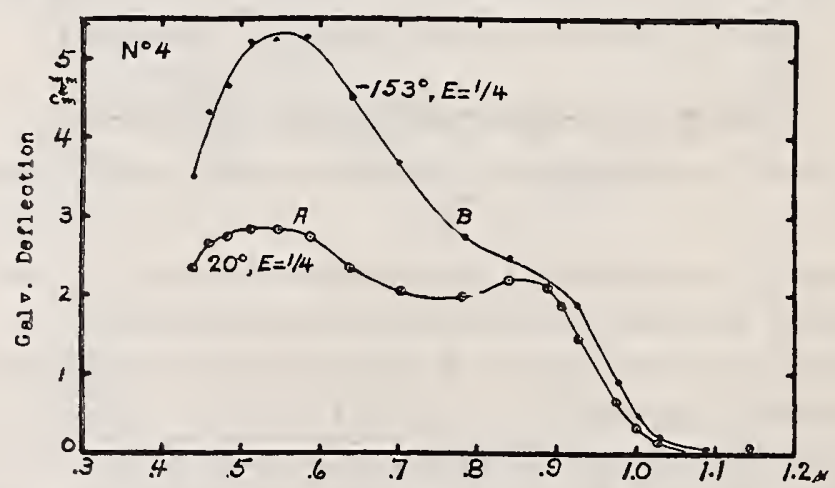

FIG. I2.-Effect of temperature upon the spectrophoto-electrical sensitivity of bournonite (No. 4).

centimeters for curve $B$. At low temperatures the maximun in the violet remains more intense than the one at $0.87 \mu$.

In Figure $\mathrm{I}_{3}$ are given the photo-electrical sensitivity curves of bournonite sample No. 5 at $19^{\circ} \mathrm{C}$. and $-162^{\circ} \mathrm{C}$., respectively. In this illustration the observed galvanometer deflections at $-162^{\circ} \mathrm{C}$. were twice the indicated scale of ordinates. As ob- 
served in other samples of bournonite, both sensitivity maxima shift toward the shorter wave lengths, and the one in the violet remains the more intense with decrease in temperature.

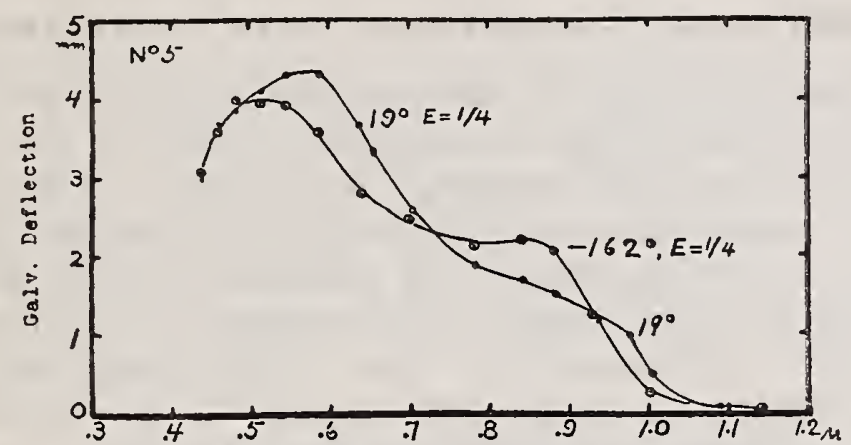

FIG. I3.-Effect of temperature upon the spectrophoto-electrical sensitivity of bournonite (No. 5).

\section{OBSERVATIONS IN THE ULTRA-VIOLET.}

Using the previously mentioned quartz spectro-pyrheliometer, the ultra-violet spectrophoto-electrical sensitivity of five samples

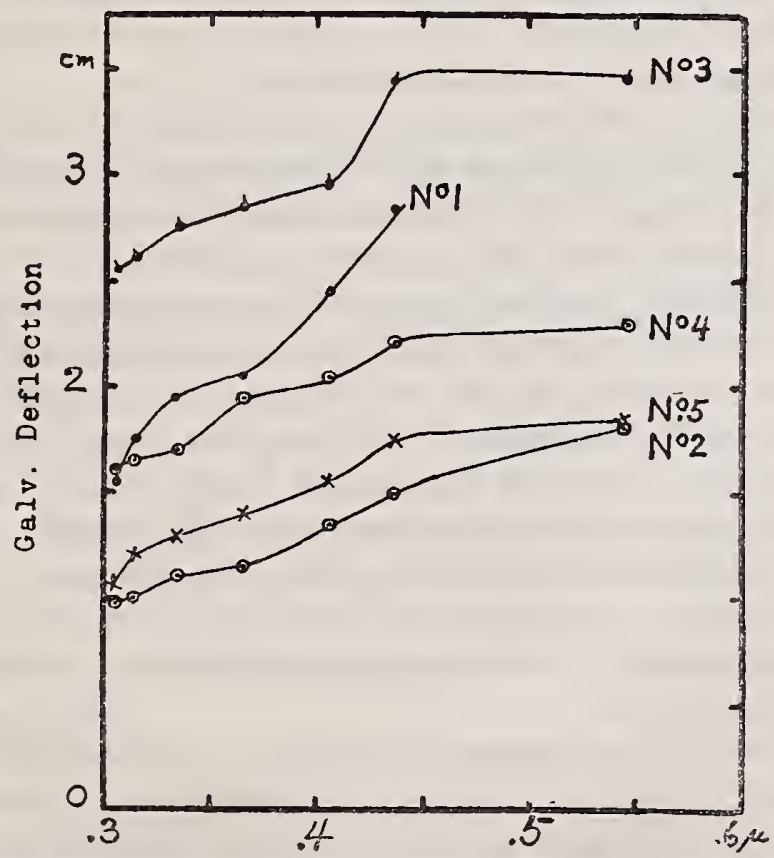

FIG. I4.-Photo-electrical sensitivity of bournonite in the ultra-violet spectrum.

of bournonite was determined at room temperature. The observations are illustrated in Figure I4. All the data are in good agreement with the measurements made with the mirror spec- 
trometer, showing that the photo-electrical sensitivity of bournonite is considerably less in the ultra-violet than in the visible spectrum.

\section{SPECTROPHOTO-ELECTRICAL DATA ON PYRARGYRITE.}

Pyrargyrite, $\mathrm{Ag}_{3} \mathrm{SbS}_{3}$, is a double sulphide of silver and antimony which crystallizes in the rhombohedral system. In thin sections it transmits red light, imparting a bright red or vermilion color. In this respect it resembles proustite, $\mathrm{Ag}_{3} \mathrm{AsS}_{3}$ (also rhombohedral), the photo-electrical properties of which mineral were previously published. ${ }^{8}$ In that paper it was neglected to point out that the sulphides of arsenic in the form of the mineral realgar, AsS (color bright red, monoclinic crystal), and the mineral orpiment, $\mathrm{As}_{2} \mathrm{~S}_{3}$ (color yellow, orthorhombic crystal), were found insensitive photo-electrically. Case ${ }^{9}$ recorded that these two minerals are not photosensitive. Nevertheless, the presence of the sulphide of arsenic in the compound formed with silver sulphide has a profound effect upon the spectrophoto-electrical reaction observed ${ }^{10}$ in silver sulphide, $\mathrm{Ag}_{2} \mathrm{~S}$, which has a high reaction in the ultraviolet with a maximum at $0.4 \mathrm{I} \mu$ and a second (more intense) maximum at $\mathrm{I} .35 \mu$ in the infra-red.

As shown in a previous paper, ${ }^{11}$ the presence of the sulphide of arsenic with the sulphide of silver, forming the mineral proustite, $\mathrm{Ag}_{3} \mathrm{AsS}_{3}$, produces a photo-electrical response spectrum which is entirely different from that of silver sulphide. In proustite the photosensitivity is confined practically to a wide maximum in the ultra-violet with a less intense maximum in the region of $0.578 \mu$ in the visible spectrum beyond which point (in the infra-red) it is photo-electrically insensitive. On the other hand, the photosensitivity of silver sulphide is confined mainly to the infra-red at I. $3 \mu$, with only a weak maximum in the ultra-violet.

In the mineral pyrargyrite, $\mathrm{Ag}_{3} \mathrm{SbS}_{3}$, the arsenic in proustite, $\mathrm{Ag}_{3} \mathrm{AsS}_{3}$, may be considered for the present to be replaced by antimony (sulphide), which is also photosensitive ${ }^{12}$ with an intense maximum at $0.77 \mu$.

As will be shown presently, the spectrophoto-electrical sensitivity curve of the compound of the sulphides of silver and of antimony, pyrargyrites, $\mathrm{Ag}_{3} \mathrm{SbS}_{3}$, is entirely different from that of the individual sulphides of silver and of animony, but in its general

\footnotetext{
B. S. Sci. Papers, 17, p. I79; I921.

11 B. S. Sci. Papers, 17, p. I79; I921

9 Case, Phys. Rev., (2) 9, p. 305; I9I7.

12 B. S. Sci. Papers, 16, p. 600 ; I920.

10 B. S. Sci. Papers, 15, p. 23I, I919; 16, p. $603,1920$.
} 
outline the sensitivity curve resembles closely that of proustite, $\mathrm{Ag}_{3} \mathrm{AsS}_{3}$.

The photo-electrical reaction spectra remind one of the results of previous researches on transmission spectra, ${ }^{13}$ in which it was shown that the absorption spectrum of a compound is not the composite of the absorption bands of the constituent elements, and that the great groups of chemically related compounds-for example, fatty acids-have similar absorption spectra. Similarly, the photo-electrical reaction spectrum of pyrargyrite, $\mathrm{Ag}_{3} \mathrm{SbS}_{3}$, is not the composite of the reactions of the constituent sulphides, but there is a great similarity in the spectral reactions of pyrargyrite and of proustite, $\mathrm{Ag}_{3} \mathrm{AsS}_{3}$.

\section{DESCRIPTION OF THE MATERIAL EXAMINED.}

The samples of pyrargyrite, $\mathrm{Ag}_{3} \mathrm{SbS}_{3}$, used in this investigation came from Freiberg, Saxony. ${ }^{14}$ Three samples were examined. They were of large, well-formed crystals, which were semitransparent and of a light vermilion color when broken into thin fragments, indicating a high absorption for wave lengths less than $0.5 \mu$.

Sample No. I was a fragment broken from a homogeneous crystal, size 5 by 3 by $2 \mathrm{~mm}$ between the electrodes. In order to attach the electrodes, the ends and a short length along the sides of all of these samples were covered with Wood's alloy, with the view of obtaining symmetrical electrical conduction through the crystal It was found that this alloy adheres well to the crystal if not applied too hot. The terminals (of No. 36 copper wire) were then soldered to these Wood's alloy electrodes.

Sample No. 2 was a single crystal with 5 well-formed faces, size I 2 by 8 by $7 \mathrm{~mm}$. Owing to its large size it was not suitable for spectral measurements, but it was found to be photo-electrically sensitive when exposed to the total radiation from a tungsten lamp.

Sample No. 3 was a fragment broken from a large crystal, size 4 by 3.5 by $2.5 \mathrm{~mm}$.

\section{REACTION-TIME.}

At room temperatures the maximum deflection on exposure to radiation was attained in 5 to 30 seconds. Similarly, the recovery after exposure was not greatly prolonged. At low temperatures,

13 Coblentz. Investigations of Infra-Red Spectra, Publs., Nos. 35, 65, and 97, Carnegie Institution of Washington, $1905-1908$.

14 Purchased from Ward's Nat. Sci. Estab., Rochester, N. Y. 
however, the time required for recovery from the reaction was twice the time required to attain the maximum deflection. In this respect the reaction is somewhat similar to that of stibnite,

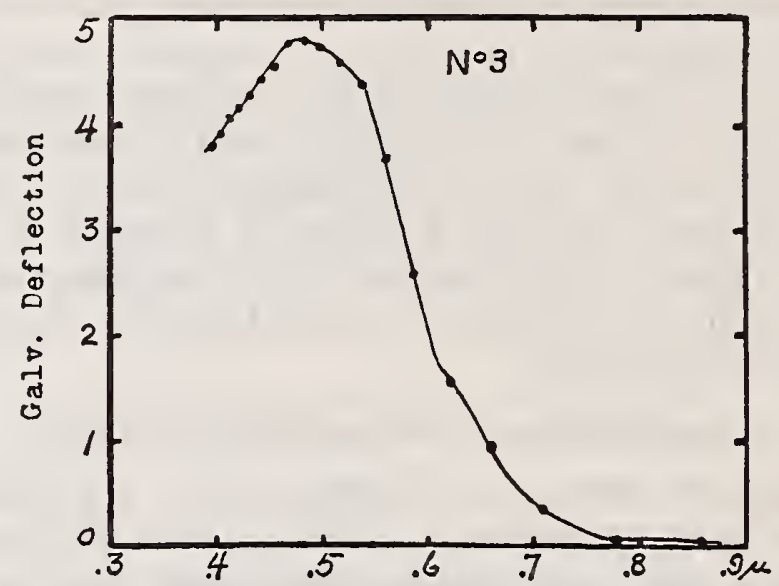

FIG. I5.-Spectrophoto-electrical sensitivity of pyrargyrite.

$\mathrm{Sb}_{2} \mathrm{~S}_{3}$, and of proustite, $\mathrm{Ag}_{3} \mathrm{AsS}_{3}$. In a general way the reaction of pyrargyrite was found to be much quicker than that of the samples of proustite previously examined.

\section{EFFECT OF INTENSITY OF THE RADIATION STIMULUS.}

The spectrophoto-electrical response curve of pyrargyrite sample No. 3 , observed with a glass prism of large dispersion and a lens

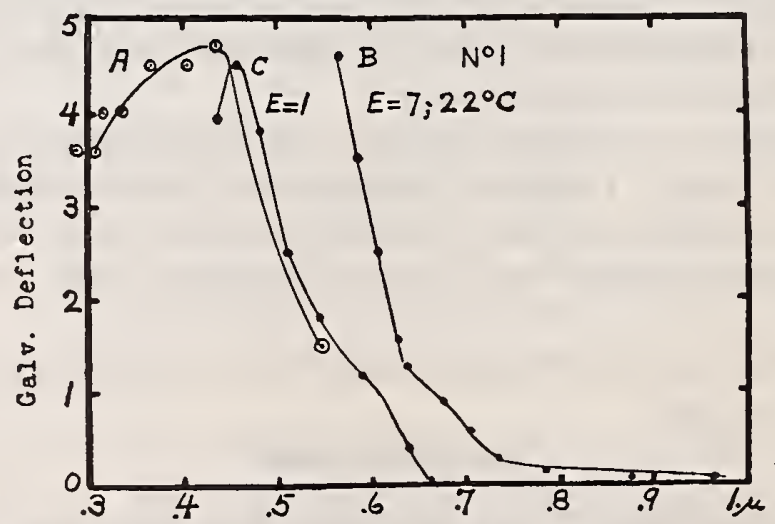

FIG. I6.-Effect of intensity upon the spectrophoto-electrical sensitivity of pyrargyrite.

spectrometer of high light-gathering power, is shown in Figure 15. The maximum is in the violet with a possible smaller maximum in the region of $0.65 \mu$, better illustrated in Figure 16. 
In Figure I6 curve $C$ gives the spectrophoto-electrical sensitivity of sample No. I, observed with a mirror spectrometer and quartz prism, using an equal energy spectrum of $E=1$. Similarly, curve $B$ gives the spectral reactions for an intensity, $\mathrm{E}=7$, the ordinates having twice the value of those of curve $C$. As previously observed on other substances there is no relation between the intensity of the radiation stimulus and the reaction at different wave lengths, and the maximum (in the region of $0.6 \mu$ ) is shifted to the long wave lengths (to $0.68 \mu$ ) on exposure to intense radiation.

Curve $A$ illustrates the behavior in the ultra-violet as observed with a quartz spectropyrheliometer using the spectral radiation lines from a quartz mercury vapor lamp. From this it appears

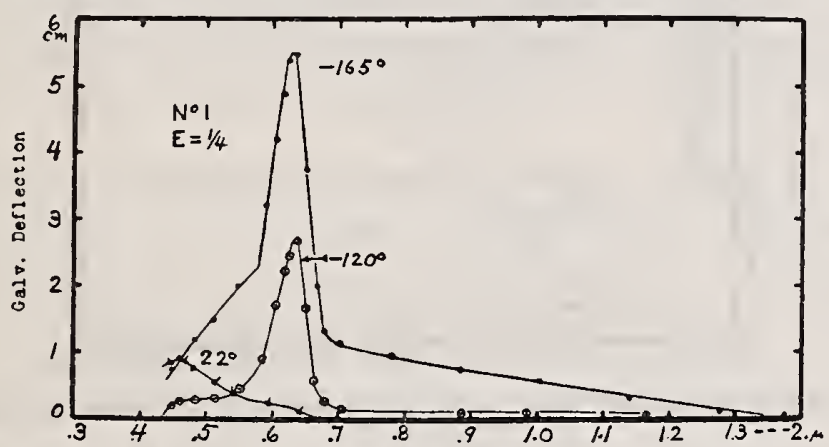

FIG. 17.-Effect of temperature upon the spectrophoto-electrical sensitivity of pyrargyrite (No. I).

that there is a wide region of photo-electrical sensitivity in the ultra-violet.

\section{EFFECT OF TEMPERATURE.}

In Figure 17 is illustrated the change in the spectrophotoelectrical reaction of pyrargyrite sample No. $\mathrm{x}$ with change in temperature. At $22^{\circ} \mathrm{C}$. the maximum photo-electrical reaction is in the violet with an inconspicuous maximum at $0.63 \mu$. As the temperature increases the intrinsic sensitivity is greatly increased throughout the spectrum. The band at $0.63 \mu$ increases rapidly in intensity and at $-165^{\circ} \mathrm{C}$. practically obliterates the ultra-violet maximum. At low temperatures this sample was photo-electrically sensitive out to $\mathrm{I} .4 \mu$ in the infra-red, but, unlike molybdenite, there does not appear to be a maximum in the deep infrared. 
The change in spectrophoto-electrical sensitivity of sample No. 3 with temperature is depicted in Figure r8. At $-35^{\circ} \mathrm{C}$. the maximum in the violet is still predominant, but at $-137^{\circ} \mathrm{C}$ it is inconspicuous in comparison with the maximum at $0.635 \mu$. In this illustration the zero ordinate of the sensitivity curve for - $137^{\circ} \mathrm{C}$. is displaced to avoid confusion.

A comparison of the curves in Figures $I 7$ and 18 shows that the sensitivity maximum at $0.63 \mu$ does not suddenly envelop the ultra-violet band at a definite temperature, but that, as the temperature decreases, there is a gradual interchange in the relative intensities of these two maxima as previously observed in proustite. ${ }^{15}$ From the data at hand it appears that within the

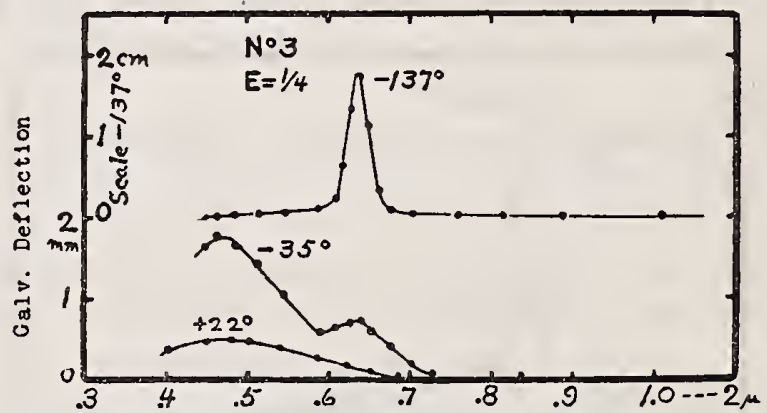

Fig. I8.-Effect of temperature upon the spectrophoto-electrical sensitivity of pyrargyrite (No. 3).

temperature range of $-45^{\circ}$ to $-60^{\circ} \mathrm{C}$. the maxima would be of equal intensity.

It is relevant to add that there is a complete agreement in the spectrophoto-electrical reactions of pyrargyrite, $\mathrm{Ag}_{3} \mathrm{SbS}_{3}$, and proustite, $\mathrm{Ag}_{3} \mathrm{AsS}_{3}$. In the latter the long wave length maximum (at low temperatures) occurs at $0.578 \mu$ as compared with $0.63 \mu$ in pyrargyrite. From this it would appear that the atomic weight of the constituents (As or $\mathrm{Sb}$ ) may have some effect upon this maximum. This is a subject that will be discussed in a future paper in connection with data mentioned in footnote No. 2.

\section{SUMMARY.}

The present paper, considered in connection with previously published data on proustite (B. S. Sci. Papers No. 4 I 2), represents a study of the effect of chemical constitution upon spectrophotoelectrical sensitivity. 
Experimental data are given on the effect of temperature and of the intensity of the radiation stimulus upon the photo-electrical sensitivity of the minerals bournonite and pyrargyrite in the spectral region extending from $0.3 \mu$ in the ultra-violet to $2 \mu$ in the infra-red.

The spectropnoto-electrical reaction curve of bournonite is entirely different from that of the constituent sulphides of copper and lead (which are not photo-sensitive) and of antimony which has its photo-electrical sensitivity confined principally to a band at $0.77 \mu$ in the extreme red. On the other hand, bournonite has a high spectrophoto-electrical sensitivity extending from the extreme violet to $\mathrm{I} \mu$ in the infra-red, with two wide, ill-defined maxima in the region of $0.55 \mu$ and $0.95 \mu$, respectively.

On lowering the temperature the intrinsic spectrophoto-electrical sensitivity of bournonite is greatly increased and the maxima shift toward the short wave lengths. The maximum in the violet usually remains the more intense at the lowest temperatures.

In common with all substances thus far examined the effect of increasing the intensity of the radiation stimulus upon the photoelectrical reaction of bournonite and pyrargyrite is to produce a more rapid increase in the response in the long wave lengths than in the short wave lengths, with a resultant shift of the spectrophoto-electrical sensitivity curve toward the long wave lengths.

The spectrophoto-electrical reaction of the mineral pyrargyrite, which is a double sulphide of silver and antimony, is entirely different from that of the constituent sulphides of silver and of antimony, which also exhibit photo-sensitivity. At $22^{\circ} \mathrm{C}$. the photo-electrical reaction of pyrargyrite consists of a wide unsymmetrical maximum in the ultra-violet, with a weak, ill-defined maximum in the region of $0.63 \mu$.

Lowering the temperature greatly increases the intrinsic photoelectrical sensitivity throughout the spectrum, and the maximum at $0.63 \mu$ increases in intensity and sharpness of outline. At low temperatures, $-165^{\circ} \mathrm{C}$., pyrargyrite reacts electrically to radiations of all wave lengths extending from the extreme ultra-violet to $I .5 \mu$ in the infra-red, but the greatest photo-electrical reaction is localized in the band at $0.63 \mu$.

There is a great similarity in the spectrophoto-electrical and chemical properties of pyrargyrite (silver-antimony sulphide) and of proustite (silver-arsenic sulphide). In a general way the fore- 
going properties of photo-electrical reaction spectra are analagous to properties of absorption spectra as affected by chemical constitution, from which it appears that perhaps ultimately the two phenomena may be traced to a common source within the molecule.

Washington, May 12, I922. 